Received 09/17/2014

Review began 09/22/2014

Review ended 09/29/2014

Published 09/30/2014

\section{(C) Copyright 2014}

Munakomi et al. This is an open access article distributed under the terms of the Creative Commons Attribution License CC-BY 3.0., which permits unrestricted use, distribution, and reproduction in any medium, provided the original author and source are credited.

\title{
Clinical Profile and Methodology in the Management of Inflammatory Benign Breast Lesions
}

\author{
Sunil Munakomi ${ }^{1}$, Shailesh Adhikary ${ }^{2}$ \\ 1. Neurological Surgery, Nobel Medical College and Teaching Hospital, Biratnagar, NPL 2. General \\ Surgery, BPKIHS, Dharan, Nepal
}

$\square$ Corresponding author: Sunil Munakomi, sunilmunakomi@gmail.com Disclosures can be found in Additional Information at the end of the article

\section{Abstract}

There is a high incidence of mammary infections among females who attend the emergency department or surgery outpatient department. Acute bacterial mastitis either resolves under antibiotic therapy or evolves towards a pyogenic abscess. Traditional treatment of breast abscesses is by surgical incision, digital disruption of septa, evacuation of contents with occasional placement of surgical drains, and administration of systemic antibiotics. This strategy often requires general anaesthesia, may leave unpleasant scars, is more expensive than aspiration, requires regular postoperative dressing changes, and interferes with lactation. Overall, about $10-38 \%$ of abscesses recur and require additional surgical drainage. Needle aspiration of the pus in breast abscesses has been reported both with and without ultrasound guidance. It causes less scarring, does not affect breast-feeding, nor does it require general anaesthesia or hospitalization. It is in fact a less expensive procedure than surgery. This study was applied to all patients with mammary infections. Ultrasound-guided drainage was done for abscesses of limited size. If the abscesses were bigger or when image-guided aspiration was not effective, they were considered for operative intervention.

Categories: General Surgery

Keywords: breast abscess, incision and drainage, aspiration

\section{Introduction}

Ultrasound-guided drainage has been described in smaller series as a treatment for breast abscesses, the treatment for which has traditionally been surgery or even less frequently, punctures without imaging guidance [1-4]. In some institutions, the standard treatment still remains early incision under general anaesthesia combined with drainage tube insertion [5]. Ultrasound-guided drainage causes less scarring, does not affect breast-feeding, nor does it require general anaesthesia or hospitalization [3]. It is in fact a less expensive procedure than surgery [6].

\section{Materials And Methods}

This was a prospective study in a tertiary referral centre, BPKIHS, Dharan, Nepal within a period of one year wherein a total of 120 breast abscess (both lactating and non-lactating) were included. This study was performed after permission from the ethical review committee, BPKIHS, was given. In Nepal, we do not have the protocol numbering system. We present the study to the ethical committee, and if reasonable, they approve it. Informed written consent was obtained from all patients. 


\section{Cureus}

\section{Inclusion criteria}

All lactational and non-lactational breast abscesses with features of:

1. Cellulitis,

2. Focal abscess,

3. Multiloculated abscess (after consent from patient regarding multiple aspirations and risk for failure).

\section{Exclusion criteria (specific and applicable to ultrasound- guided drainage group only)}

1. Recurrent breast abscess,

2. Breast abscess $>5 \mathrm{~cm}$ size,

3. Breast abscess associated with malignancy,

4. Multiloculated abscesses.

Results were formatted using the SPSS software and chi square test.

\section{Results}

\section{Ultrasonography findings}

Ultrasonography (USG) helped us confirm the diagnosis as well as in locating the site of absess, to assess its size and volume, and also in the follow-up to quantify the amount of remnant collection (Figure 1). USG showed evidence of unilocular abscess in 77 (64\%), multilocular abscess in 30 (25\%), and mastitis in 13 (11\%) of patients.

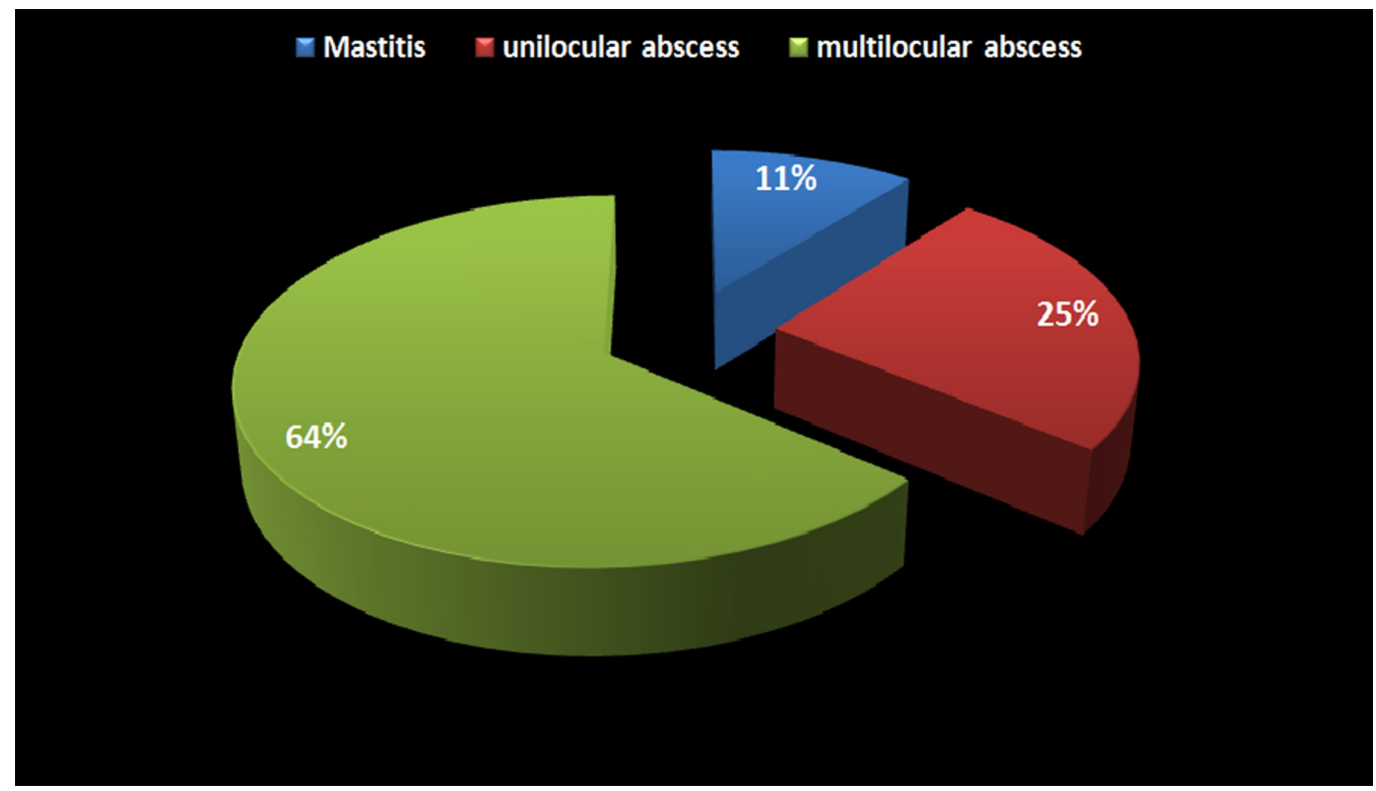

FIGURE 1: Ultrasonography Findings 


\section{Cureus}

\section{Mode of management}

Among all the selected patients, 57 (47\%) were managed by incision and drainage, 50 (42\%) had undergone aspiration, and 13 (11\%) were treated non-operatively (Figure 2).

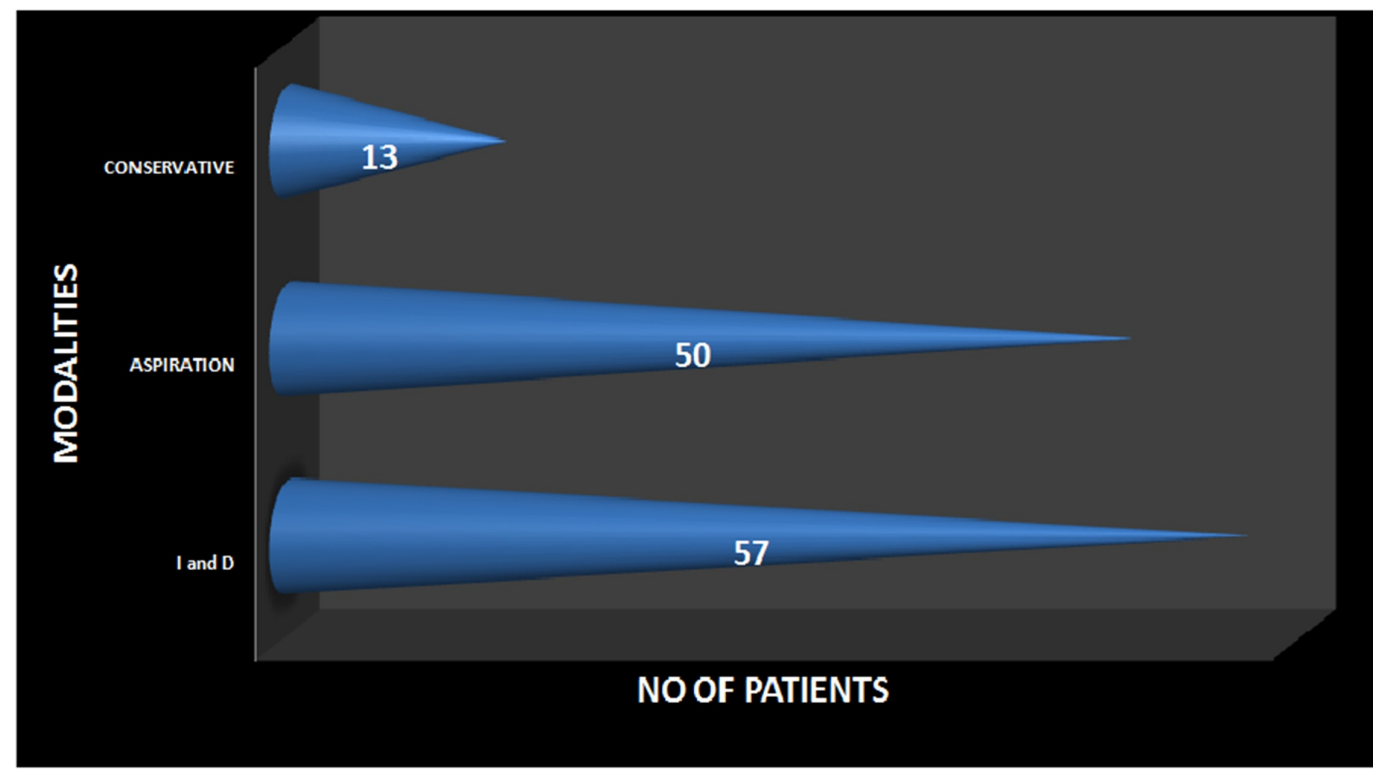

FIGURE 2: Modalities of management

\section{Number of aspirations}

Among the aspiration group, single aspiration was required in 11 (22\%) patients, two aspirations were required in 14 (28\%), three were required for 19 (38\%) of patients, and six patients required aspiration up to four times (Figure 3). Six (12\%) of the group were considered failure of management and were finally under taken for incision and drainage.

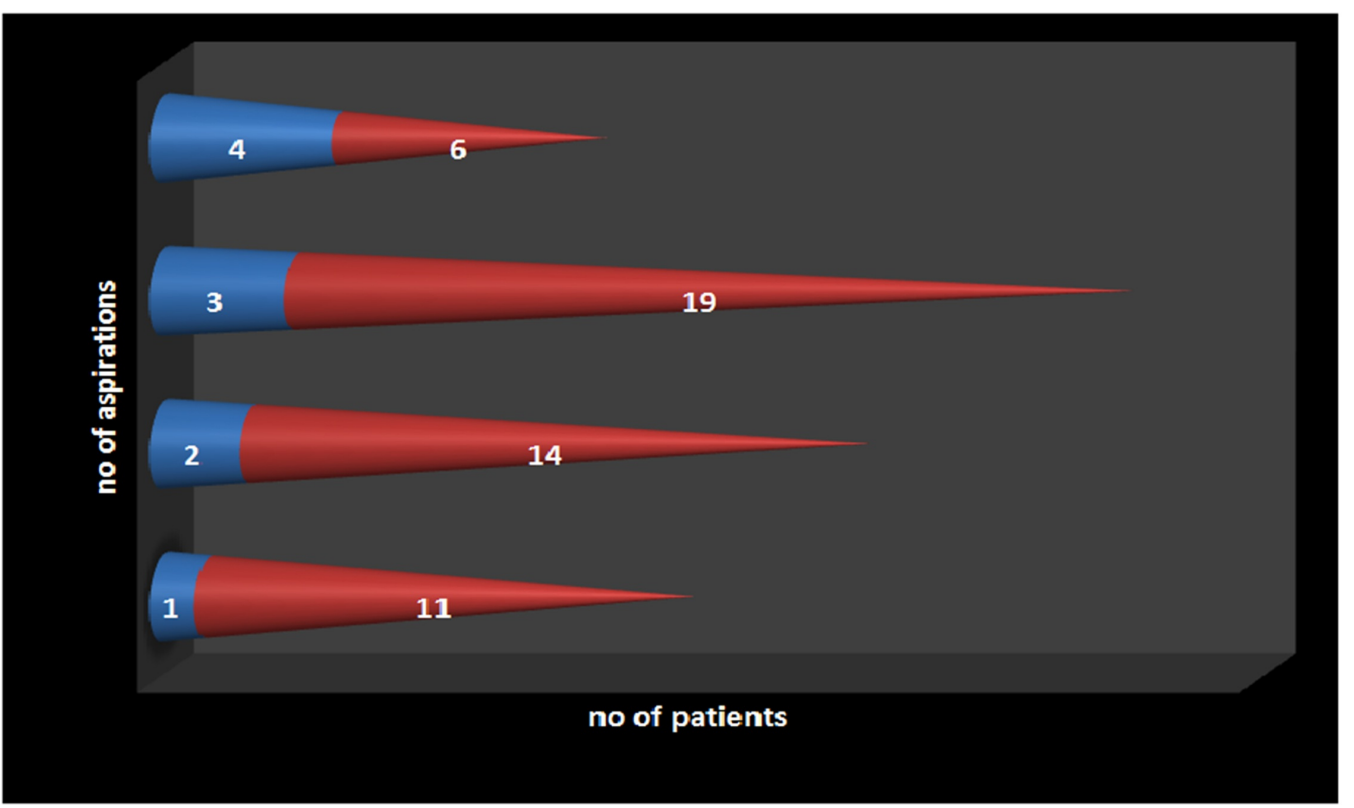




\section{Cureus}

FIGURE 3: Number of aspirations required

\section{Profile of the failure group in relation to abscess size}

There were no failures in abscess less than $3 \mathrm{~cm}$ size, which was statistically significant $(p=0.008)$ when compared to other sizes. One failure (3.2\%) was seen in an abscess size of 3-4 $\mathrm{cm}$. Five (10\%) failures were seen in abscess size $>4 \mathrm{~cm}$ (31\%) (Figure 4 ).

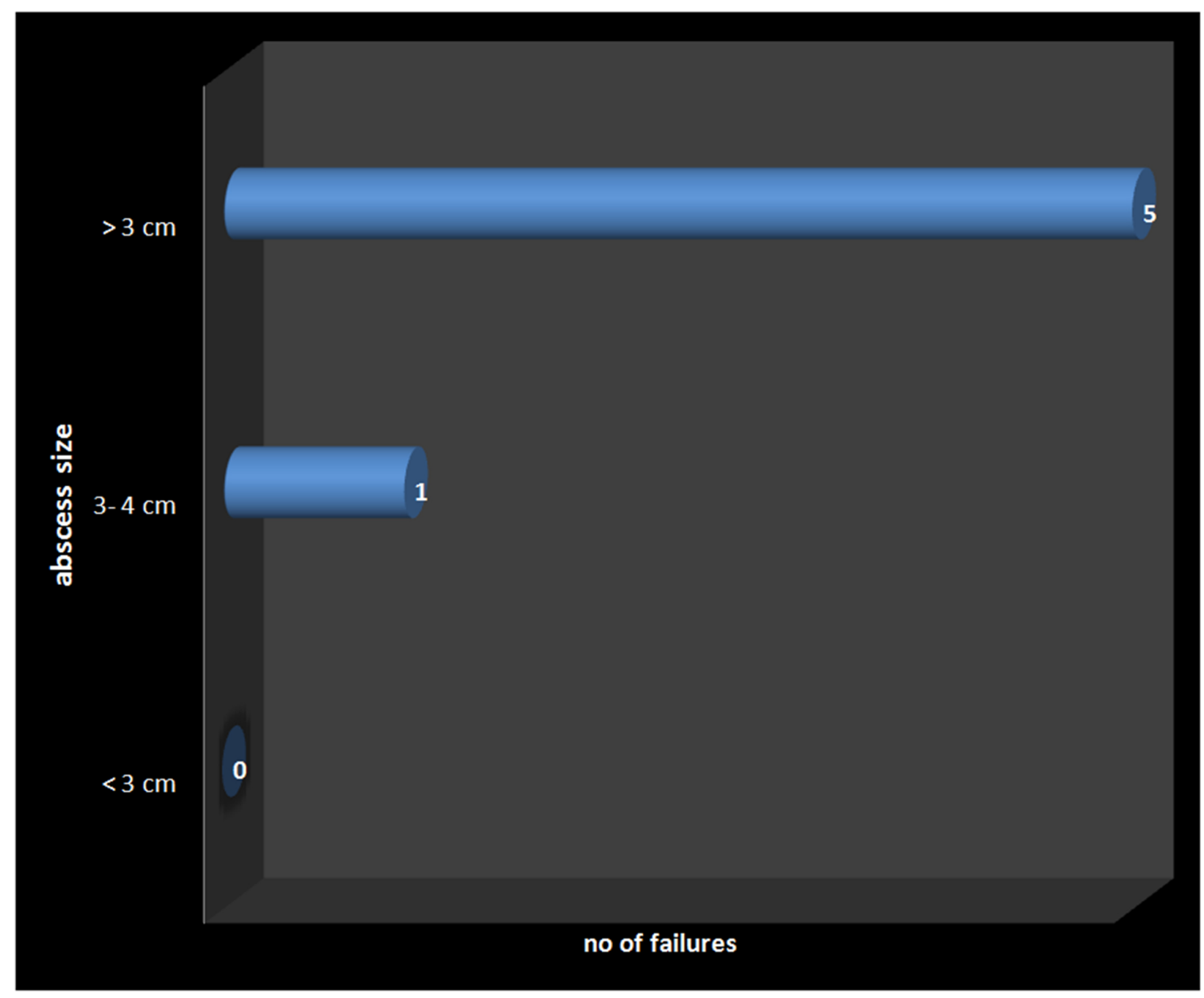

FIGURE 4: Profile of the failure group in relation to abscess size

\section{Profile of the failures in the aspiration group}

A profile of the failures is shown in Table 1. In two cases, there was evidence of multi-locularity in the subsequent scans. In two cases, there was sub-areolar abscess with impending rupture that was managed by incision and drainage. Two patients were finally taken up for incision and drainage on request as regular follow-up for repeated aspiration was not possible for them. 


\section{Cureus}

\begin{tabular}{|c|c|c|c|}
\hline Duration of symptoms (days) & Size of abscess $(\mathrm{cm})$ & Amount Drained (ml) & Causes of failure \\
\hline 7 & $5 \times 4$ & 18 & Multiloculated \\
\hline 9 & $5 \times 4$ & 18 & Multiloculated \\
\hline 7 & $4 \times 4$ & 18 & Subareolar \\
\hline 7 & $5 \times 4$ & 16 & Subareoral \\
\hline 8 & $5 \times 5$ & 15 & Refusal to treatment \\
\hline 9 & $5 \times 5$ & 16 & Refusal to treatment \\
\hline
\end{tabular}

TABLE 1: Profile of Failures in the Aspiration Group

\section{Success rates of different treatment modalities}

Two patients who were treated non-operatively had to be taken for aspiration as subsequent examination showed evidence of collection. There were two recurrences in the incision and drainage group, and they had to be admitted for systemic antibiotics due to large residual abscess cavity. Overall success rate was highest for incision and drainage group compared to the aspiration group but it was not statistically significant ( $\mathrm{p}=0.64)$ (Figure 5).

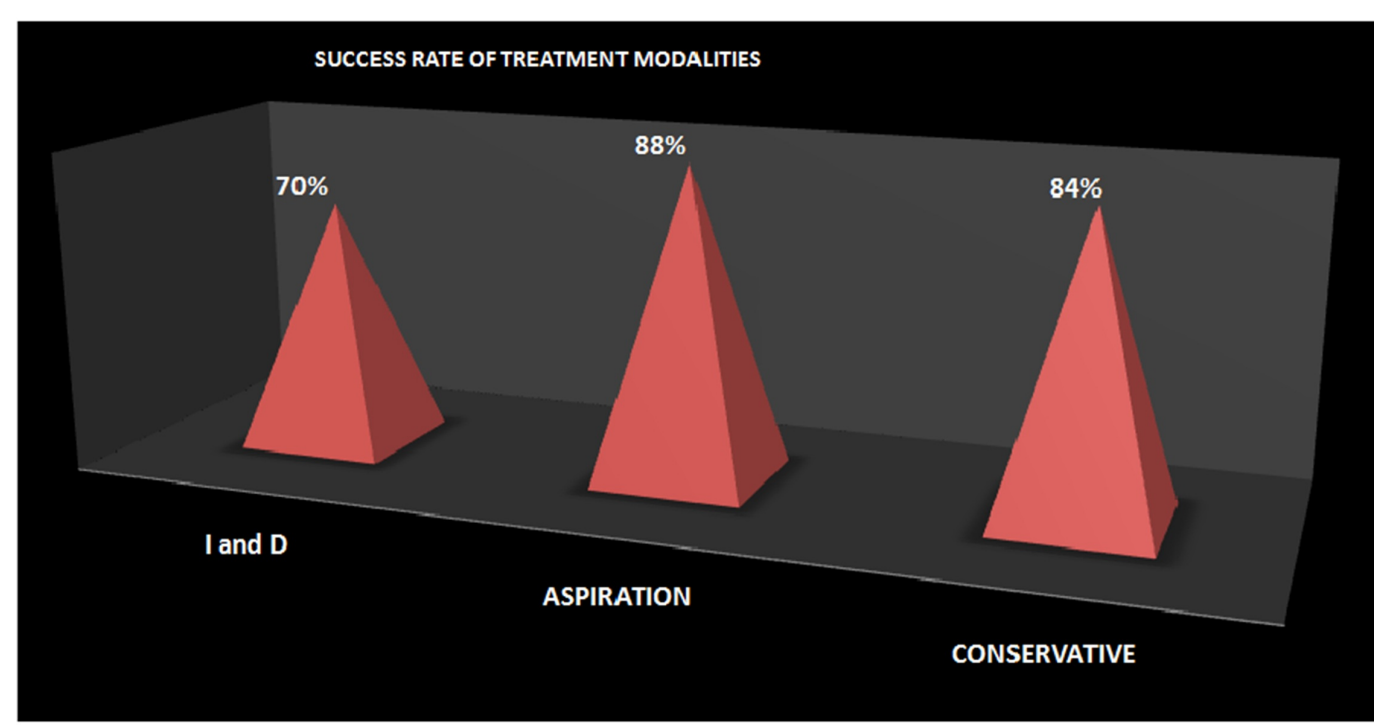

FIGURE 5: Success rate of different treatment modalities

\section{Overall patient satisfactions for treatment}

The overall patient satisfaction in each group is shown below in Figure 6. Patient satisfaction was highest for the aspiration group (88\%) followed by the non-operative group (84\%), and it was statistically significant ( $\mathrm{p}=0.023)$. Only 40 (70\%) patients were found to be satisfied with 


\section{Cureus}

incision and drainage as it is demonstrated in Table 1.

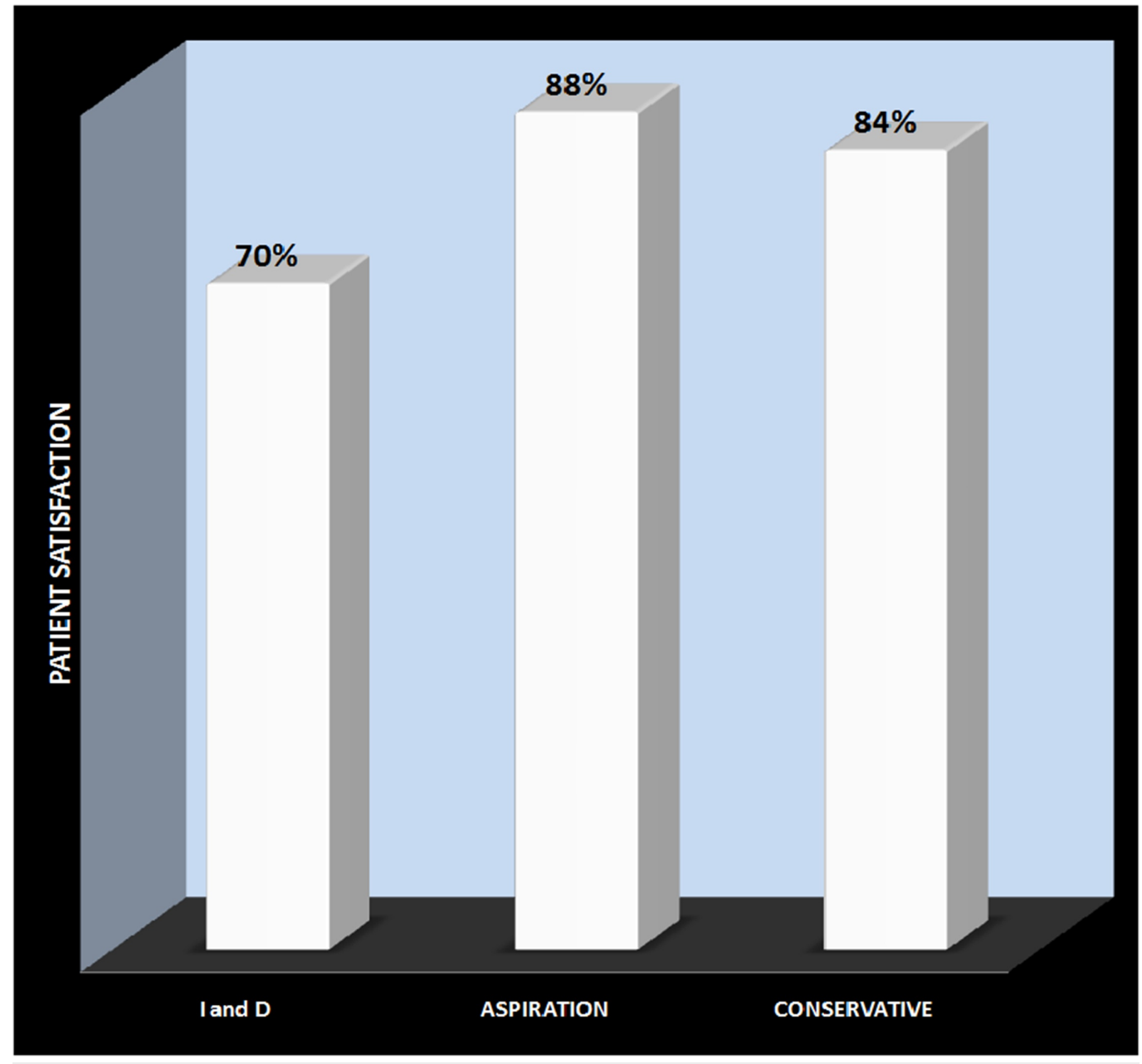

FIGURE 6: Overall patient satisfaction in different groups

\section{Effects of the treatment modalities on continuation of lactation}

The effects of treatment modalities on cessation of lactation is shown in Figure 7. Cessation of lactation was seen only in eight patients (16\%) in the aspiration group compared to 57 (100\%) in the case of the incision and drainage group. All the patients never discontinued breastfeeding in the non-operative group. 


\section{Cureus}

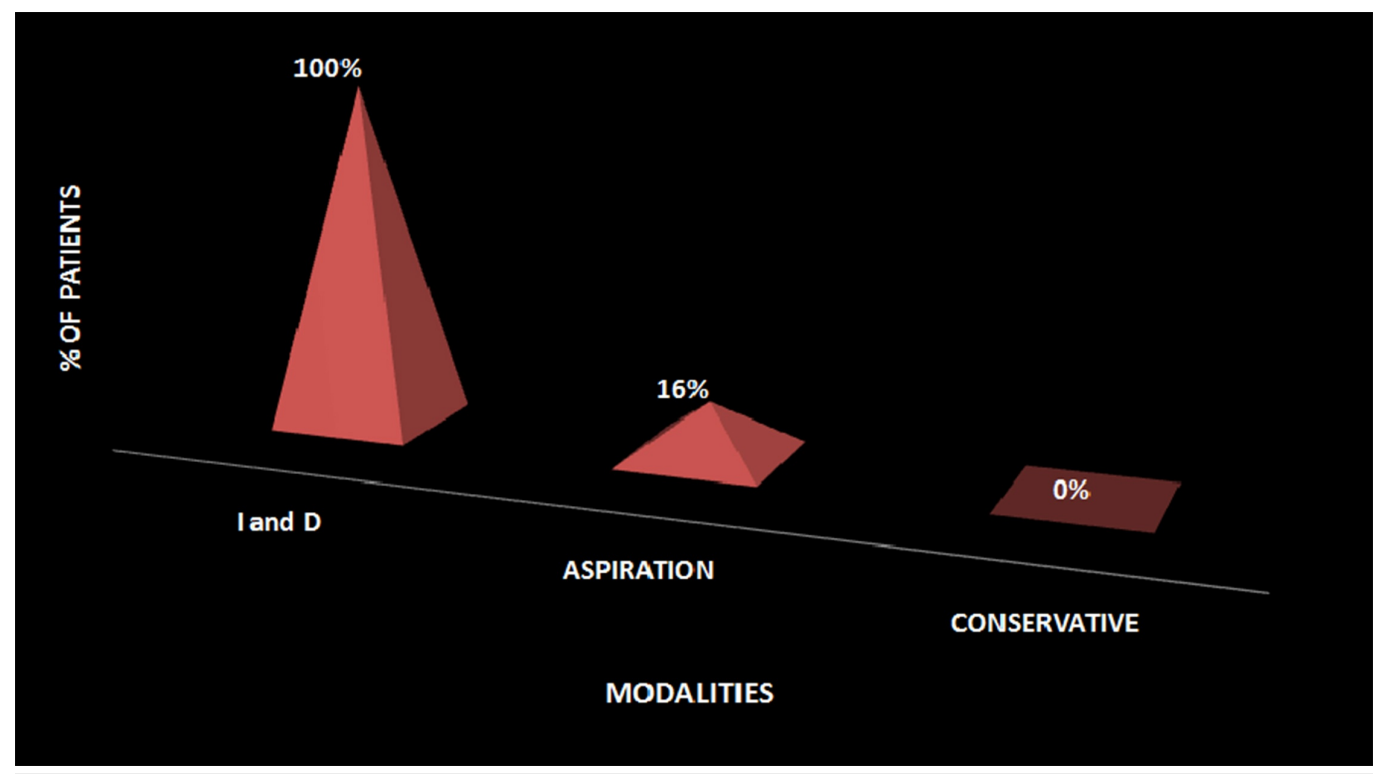

\section{FIGURE 7: Effect of treatment modalities on cessation of lactation}

\section{Patient's satisfaction in aspiration group}

Thirty (60\%) of the patients tolerated the procedure well, although 20 (40\%) cases complained of mild discomfort at the needle insertion site.

All of the patients who were successfully treated with aspiration were satisfied with the cosmetic outcome of their breasts. The majority (30 patients - 60\%) of them were satisfied despite their frequent hospital visits, but 20 (40\%) of them had some socioeconomic and transport issues.

\section{Discussion}

High-resolution real-time sonography is a unique means for diagnosing and evaluating the extent, site, size, and internal characteristics of breast abscesses. The possibility of using sonographically-guided percutaneous aspiration has emerged as a valid alternative to surgical drainage. As far as we know, Karstrup, et al. [7] first reported the successful use of this technique in 1990, soon followed by other investigators. More recently, Imperiale, et al. [2] resurrected the local instillation of antibiotics (40-160 mg of gentamicin) after sonographically-guided percutaneous aspiration in 26 patients with non-puerperal abscesses in whom systemic antibiotics failed, with only one failure requiring surgical drainage. Karstrup, et al. [7] recommended continuous catheter drainage and irrigation of 20 puerperal abscesses using pigtail catheters that were placed for a median duration of four days. A 95\% success rate was reported in that series. Forty-two percent of patients continued to breast-feed their infants.

O'Hara, et al. [8] reported a 85\% cure rate of 22 abscesses, some of them aspirated without sonographic guidance. Schwarz and Shrestha [9] also reported aspiration without sonographic guidance, plus oral antibiotics, in 33 abscesses with a resultant cure rate of $82 \%$. Their success rate statistically correlated with a mean volume of pus at the first aspirate of $4.6 \mathrm{~mL}$, compared with failures in abscesses with a mean volume of $21.5 \mathrm{~mL}$. Hook and Ikeda [10] reported a 54\% cure rate of 13 breast abscesses treated by aspiration and irrigation. The patients in whom 
treatment failed had an abscess of more than $3 \mathrm{~cm}$ in diameter. Dixon [4], however, reported successful aspiration of six lactating abscesses with a mean volume of $26 \mathrm{~mL}$.

\section{Conclusions}

Breast abscesses smaller than $3 \mathrm{~cm}$ with no evidence of skin changes or multi-locularity can be taken up for ultrasound-guided aspirations provided there is feasibility for regular follow-up.

\section{Additional Information \\ Disclosures}

Human subjects: Consent was obtained by all participants in this study. BPKIHS Ethical Committee Review Board issued approval This study was cleared by the BPKIHS Ethical Committee Review Board. In Nepal, we do not have the protocol numbering system. We present the study to the ethical committee, and if reasonable, they approve it. Animal subjects: All authors have confirmed that this study did not involve animal subjects or tissue. Conflicts of interest: In compliance with the ICMJE uniform disclosure form, all authors declare the following: Payment/services info: All authors have declared that no financial support was received from any organization for the submitted work. Financial relationships: All authors have declared that they have no financial relationships at present or within the previous three years with any organizations that might have an interest in the submitted work. Other relationships: All authors have declared that there are no other relationships or activities that could appear to have influenced the submitted work.

\section{References}

1. Marchant DJ: Inflammation of the breast. Obstet Gynecol Clin North Am. 2002, 29:89-102.

2. Imperiale A, Zandrino F, Calabrese M, Parodi G, Massa T: Abscesses of the breast. US-guided serial percutaneous aspiration and local antibiotic therapy after unsuccessful systemic antibiotic therapy. Acta Radiol. 2001, 42:161-5.

3. Locker AP, Galea MH, Ellis IO, Holliday HW, Elston CW, Blamey RW: Microdochectomy for single-duct discharge from the nipple. Br J Surg. 1988, 75:700-1.

4. Dixon JM: Outpatient treatment of non-lactational breast abscesses . Br J Surg. 1992, 79:56-7.

5. Watt-Boolsen S, Rasmussen NR, Blichert-Toft M: Primary periareolar abscess in the nonlactating breast: Risk of recurrence. Am J Surg. 1987, 153:571-3.

6. Crowe DJ, Helvie MA, Wilson TE: Breast infection. Mammographic and sonographic findings with clinical correlation. Invest Radiol. 1995, 30:582-7.

7. Karstrup S, Solvig J, Nolsøe CP, Nilsson P, Khattar S, Loren I, Nilsson A, Court-Payen M: Acute puerperal breast abscesses: US-guided drainage. Radiology. 1993, 188:807-9.

8. O'Hara RJ, Dexter SP, Fox JN: Conservative management of infective mastitis and breast abscesses after ultrasonographic assessment. Br J Surg. 1996, 83:1413-4.

9. Schwarz RJ, Shrestha R: Needle aspiration of breast abscesses . Am J Surg. 2001, 182:117-9.

10. Hook GW, Ikeda DM: Treatment of breast abscesses with US-guided percutaneous needle drainage without indwelling catheter placement. Radiology. 1999, 213:579-82. 